\title{
The correlation between photocatalytic oxidation performance and chemical/physical properties of indoor volatile organic compounds
}

\author{
Kuo-Pin Yu, Grace W.M. Lee*, Wei-Ming Huang, Chihcheng Wu, Shinhao Yang \\ Graduate Institute of Environmental Engineering, National Taiwan University, 71, Chou-Shan Road, Taipei, Taiwan, ROC
}

Received 17 November 2004; received in revised form 9 September 2005; accepted 23 September 2005

\begin{abstract}
In this study, six species of volatile organic compounds (VOCs), $n$-hexane, iso-butanol, toluene, $p$-xylene, $m$-xylene, and mesitylene, were selected as the target pollutants to investigate how the photocatalytic oxidation (PCO) performance is related to their physical/chemical properties. The PCO kinetics were well fit by a Langmuir-Hinshelwood (L-H) model for bimolecular surface reaction and competitive adsorption at gas flow rate above $1000 \mathrm{~mL} \mathrm{~min}^{-1}$ (reaction-controlling region), where the gas-phase mass transfer effect was negligible. The rate constants of PCO for toluene, $p$-xylene, $m$-xylene, and mesitylene ranged from 1.22 to $4.00 \mu \mathrm{mol} \mathrm{m}^{-2} \mathrm{~s}^{-1}$, and were proportional to VOC-hydroxyl radical rate constant $\left(k_{\mathrm{OH}}\right)$. The Langmuir adsorption constants of the four aromatic VOCs investigated and water ranged from 0.95 to $1.35 \mathrm{ppm}^{-1}$ and from $5.61 \times 10^{-3}$ to $1.44 \times 10^{-3} \mathrm{ppm}^{-1}$, respectively. A strongly linear positive relationship was found between the reciprocal of the Langmuir adsorption constants of the four aromatic VOCs investigated and Henry's Law constants. Conversely, the reciprocal of Langmuir adsorption constants of water showed a strong negative relationship with Henry's Law constants (in units $\mathrm{kPa} \mathrm{m}^{3} \mathrm{~mol}^{-1}$ ) of the four aromatic VOCs investigated. The relationships noted above were not found between different classes of VOCs ( $n$-hexane, iso-butanol, and aromatic VOCs investigated). The percentage of residual intermediates (partially oxidized and incompletely mineralized organic compound from the primary VOCs) decreased as the inlet VOCs concentration decreased.
\end{abstract}

(C) 2005 Elsevier Ltd. All rights reserved.

Keywords: Aromatic hydrocarbons; Langmuir-Hinshelwood model; Henry's Law constant; Hydroxyl radical; Photocatalytic rate constant; $\mathrm{CO}_{2}$ yield rate

\section{Introduction}

Volatile organic compounds (VOCs) were defined as organic compounds with boiling points range from around 50 to $260^{\circ} \mathrm{C}(\mathrm{WHO}, 1989)$. VOCs are

\footnotetext{
*Corresponding author. Tel./fax: + 886223661544.

E-mail addresses: f89541105@ntu.edu.tw (K.-P. Yu), gracelee@ntu.edu.tw (G.W.M. Lee).
}

omnipresent indoors and relevant to the aggravation of indoor air quality (IAQ). The major sources of indoor VOCs include infiltration of outdoor air pollutants, byproducts of combustion emission during cooking or space heating, emissions from building materials and furniture, and biological sources such as human activity, plants and molds (Hines et al., 1993; Wolkoff and Nielsen, 2001). Long-term exposure to indoor VOCs might lead to 
symptoms such as headache, respiratory tract irritation, dizziness and nausea, which is known as the sick building syndrome (SBS) (Repace, 1982; Kim et al., 2001). Furthermore, numerous VOCs, especially some aromatics and halogenated compounds, have been proven to be carcinogens and mutagens (Hines et al., 1993).

In order to remove VOCs, many air-cleaning techniques have been developed and used in indoor environments. One of them is photocatalytic oxidation (PCO), which is widely used in recent years. PCO uses photons with energy greater than the band gap of a semiconductor to promote valence electrons to the conduction band and thus forming electrons and holes to initiate oxidation-reduction reactions. Reactive free radicals formed at the surface further oxidize and destroy VOCs. $\mathrm{TiO}_{2}$ is the most common semiconductor used as photocatalyst for PCO because of its high level of photoconductivity, ready availability, low toxicity, and low cost. PCO, rather than adsorbing VOCs on absorbent such as active carbon, oxidizes VOCs to $\mathrm{CO}_{2}$ and $\mathrm{H}_{2} \mathrm{O}$ and may produces some partially oxidized hydrocarbons such as aldehydes and ketones (Zhao and Yang, 2003; Maira et al., 2001). Compared with other oxidation methods such as ozonization (Boeniger, 1995; Wolkoff et al., 2000), the removal efficiencies of PCO for most indoor VOCs are relatively high and the production of byproducts is relatively low (Alberici and Jardim, 1997).

As PCO technology is more common used systematic methods to predict the PCO reaction rates would be useful in air-cleaning device design. According to previous research, there are many factors (e.g. characteristics of photocatalyst, species of VOCs, humidity, temperature, UV light intensity and wavelength, the ratio of catalyst surface area to the photoreactor volume, gas flow rate, and retention time, etc.) relevant to the removal efficiency of VOCs by PCO (Al-Ekabi et al., 1993; Obee and Brown, 1995; Alberici and Jardim, 1997; Peral et al., 1997; Sattler and Liljestrand, 2003). Previous studies have been conducted using a variety of photocatalysts, VOCs species, photoreactors, and environmental conditions. Thus, it is difficult to generalize these results and use them to predict PCO reaction rate under typical indoor environmental condition. Sattler and Liljestrand (2003) developed a method, based on pseudo firstorder kinetics form, to predict the PCO rate of VOCs. However, the VOCs concentration and relative humidity $(\mathrm{RH})$ conditions they used (VOCs $>10 \mathrm{ppm}, \mathrm{RH}=100 \%$ ) were much higher than those found in indoor environments. Zhang et al. (2003) and Yang et al. (2004) developed another PCO reactor model based on first-order reaction with a constant rate coefficient, and demonstrate that the fractional conversion and the number of mass transfer units are the major influential parameters for PCO performance. The assumption that the PCO reaction is a first-order reaction is reasonable for some PCO reactor, however, it not always applicable. The kinetic profile of many VOCs follows the Langmuir-Hinlshewood model, which adds Langmuir adsorption constants in the rate equation (Alberici and Jardim, 1997; Obee and Brown, 1995). In this study, we modified Sattler and Liljestrand's (2003) experimental design and developed another method, based upon LangmuirHinlshewood model, to predict the PCO rate under conditions applicable for indoor environments.

Indoor VOCs identified in office buildings and the emissions from building materials commonly include aromatic hydrocarbons (Mølhave, 1979; Mølhave et al., 1986; Jones, 1999). According to field studies of the most ubiquitous indoor VOCs, we chose toluene, $p$-xylene, $m$-xylene, and 1,3,5trimethylbenzene (or mesitylene) as the aromatic target pollutants (Wolkoff and Nielsen, 2001). nHexane was selected as the surrogate of aliphatic compounds, and iso-butanol was chosen as the representative of alcohol (VanOsdell, 1994; Wolkoff and Nielsen, 2001). The experiments were conducted with different gas flow rates, $\mathrm{RH}$, and concentration of VOCs. Some unwanted residual intermediates (partially oxidized compounds) were found in PCO reaction. Hence we also attempted to optimize operative conditions to enhance the oxidation of residual intermediates in this study.

\section{Methodology}

We used a $45-\mathrm{cm}$ long quartz photoreactor with a $2.5 \mathrm{~cm}$ interior diameter to conduct the experiments. Quartz was chosen as the photoreactor material because of its high transmittance for UV light. A $107.5 \mathrm{~cm}^{2}(43 \mathrm{~cm} \times 2.5 \mathrm{~cm})$ glass plate coated with Degussa P25 $\mathrm{TiO}_{2}$ photocatalyst was set in the middle of the photoreactor, and the lower half part of the photoreactor was filled with Teflon, inert material, to make the gas pass only through the upper part of the tube, as shown in Fig. 1(b). Degussa $\mathrm{P} 25 \mathrm{TiO}_{2}$ powder has a primary particle 


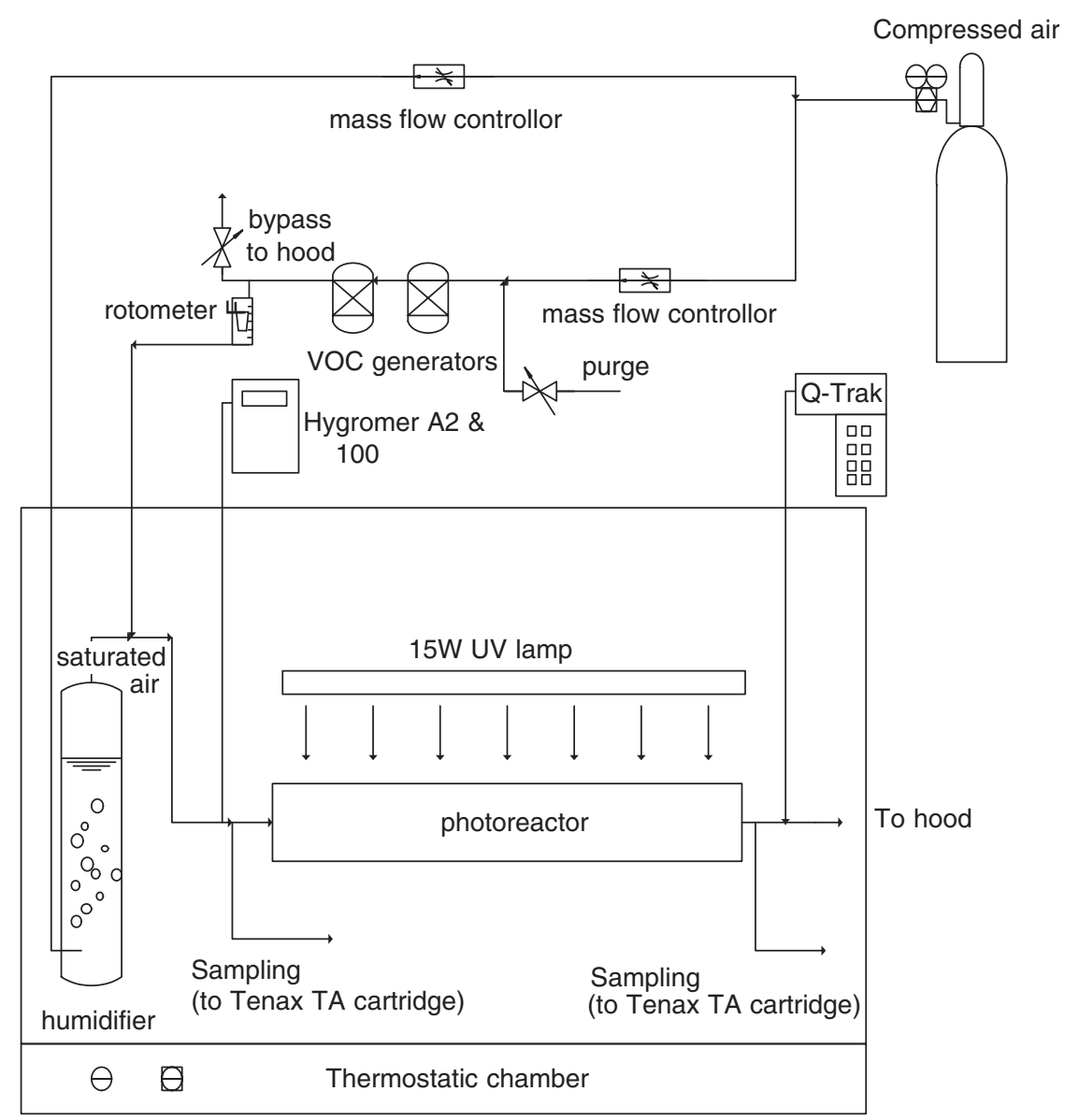

(a)

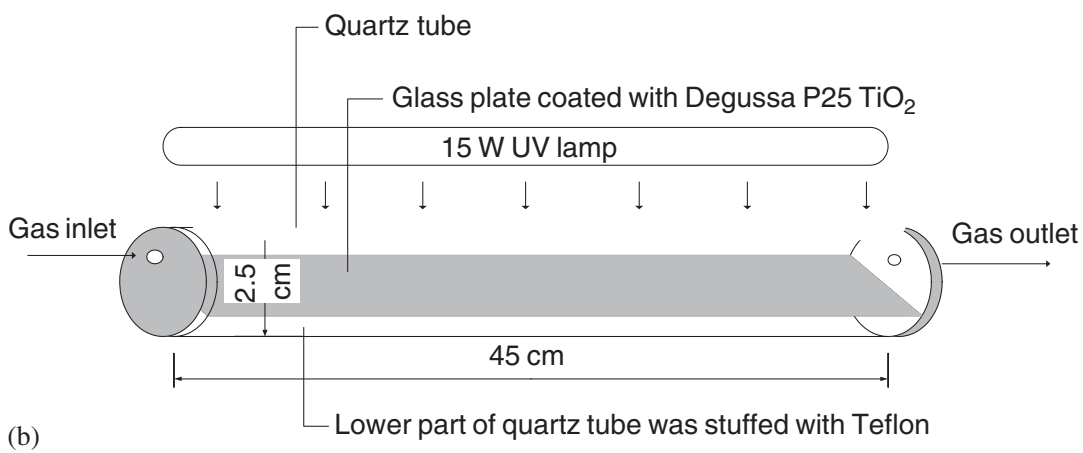

Fig. 1. Schematic diagram of (a) experimental system and (b) photoreactor.

diameter of $30 \mathrm{~nm}$, a surface area of $50 \mathrm{~m}^{2} \mathrm{~g}^{-1}$ (BET), and a crystal structure of $70 \%$ anatase and $30 \%$ rutile (Alberici and Jardim, 1997; Obee and Brown, 1995). The $\mathrm{TiO}_{2}$ coating procedure of Sattler and Liljestrand (2003) was used, as described as follows. First, the $\mathrm{TiO}_{2}$ powder was suspended in distilled water by using an ultrasonic bath (Branson 5200). Then, the glass plate was immersed in the
$\mathrm{TiO}_{2}$ suspension. After the water evaporated and the surface of the glass plate became dry, a $\mathrm{TiO}_{2}$ coating remained on the surface of glass plate. The glass plate was weighted before and after the coating procedure. The amount of photocatalyst loading was $0.0818 \mathrm{mg} \mathrm{cm}^{-2}$.

We used a $15-\mathrm{W}, \mathrm{UV}-\mathrm{C}$ (the central wavelength is $254 \mathrm{~nm}$ ), long-life strip light bulb (Phillips) to 
illuminate and activate the photocatalyst. A photon of a wavelength of $376 \mathrm{~nm}$ or lower has sufficient energy for the electron in the valence band of $\mathrm{TiO}_{2}$ to jump to the conductive band. The absorbance of $\mathrm{TiO}_{2}$ is greatest at $254 \mathrm{~nm}$ (wavelength of the photon) (Salinaro et al., 1999). The UV intensity was measured by UVX radiometer Model UVX-36 (UVP).

We selected toluene (assay 99.7\%, Riedel-deHaën), $m$-xylene (assay 98\%, Fluka), $p$-xylene (assay 98\%, Fluka), mesitylene (assay 98\%, Fluka), $n$-hexane (assay 98\%, Mallinckrodt), and isobutanol (assay 99.9\%, J.T. Baker) as the tested VOCs species. The VOCs vapor was generated using diffusion vials (VICI), and the VOCs concentration was controlled by the temperature of a water bath (DENG TNG Instruments Co., Ltd) and the gas flow rates. The VOC concentrations used in this study ranged from 0.1 to $9.0 \mathrm{ppm}$. The $\mathrm{RH}$ of the system was controlled by the ratio of the dry- and humidity-saturated gas flow rates. The temperature of the photoreactor system was controlled at $25 \pm 0.5^{\circ} \mathrm{C}$ by a thermostatic chamber (DENG TNG Instruments Co., Ltd). We used Hygromer A2 \& 100A to monitor the temperature and humidity of the inlet gas. The gas samples were taken at the inlet and the outlet of the photoreactor on the Tenax TA (60/80 mesh) cartridges (SUPEL$\mathrm{CO})$. Before used, the sampling cartridges were conditioned at $230{ }^{\circ} \mathrm{C}$ with nitrogen gas $(99.9 \%)$ flushed for $14-16 \mathrm{~h}$. After sampled, the Tenax TA cartridges were thermally desorbed and the VOCs cryofocussed using a TEKMAR 6000 Aero Trap Desorber, and then the VOCs were analyzed using a HP5890 series II gas chromatograph with a flame ionization detector (GC-FID). The column used was a $30 \mathrm{~m}$, SPB-5 column with a $0.53 \mathrm{~mm}$ interior diameter, and $0.5 \mu \mathrm{m}$ film thickness (SUPELCO). The Q-Trak 8551 (TSI) was used to monitor the $\mathrm{CO}_{2}$ yield. The experimental system used is as diagramed in Fig. 1(a).

\section{Results and discussion}

\subsection{Effect of the flow rate}

Fig. 2(a) showed the apparent oxidation rates of VOCs under different flow rates. The oxidation rate was calculated by the following equation:

$r=\frac{\left(C_{\text {in }}-C_{\text {out }}\right) Q}{F \times A}$, where $C_{\text {in }}$ and $C_{\text {out }}(\mathrm{ppm})$ are the inlet and outlet VOC concentration, $Q\left(\mathrm{~m}^{3} \mathrm{~s}^{-1}\right)$ the flow rate, $F$ the conversion factor $\left(=24500 \mathrm{ppm} \mathrm{m}^{3} \mathrm{~mol}^{-1}\right.$, this is derived from the fact that $1 \mathrm{ppm}=4.09 \times$ $\left.10^{-5} \mathrm{~mol} \mathrm{~m}^{-3}\right)$, and $A\left(\mathrm{~m}^{2}\right)$ the photocatalyst-coated area. The experiments were conducted with $5 \mathrm{ppm}$ of toluene, $p$-xylene, $m$-xylene, mesitylene, $n$-hexane and iso-butanol, respectively. In heterogeneous catalytic reactions, the apparent oxidation rate depends on gas-phase mass transfer rate, or a rate limiting surface reaction rate, or both of them. As shown in Fig. 2(a), the oxidation rate increased with increasing flow rate at low flow rate range $\left(0-600 \mathrm{~mL} \mathrm{~min}^{-1}\right)$. Thus, the observed oxidation rate at low flow corresponded to the gas-phase mass transfer rate (i.e. diffusion controlling). The apparent oxidation rate did not change significantly with flow rate and achieved a plateau for flow rate above $1000 \mathrm{~mL} \mathrm{~min}^{-1}$. This indicated that the gas-phase mass transfer rate was faster than the surface reaction rate under this condition, and the observed oxidation rate corresponded to a surface reaction rate (i.e. reaction controlling). The flow rate range between surface reaction controlling and diffusioncontrolling condition is the transitional condition. Under transitional condition, the apparent oxidation rate depends on both the surface reaction rate and gas-phase mass transfer rate. To eliminate the disturbance of gas-phase mass transfer effects, the following experiments were conducted at the flow rate of $1200 \mathrm{~mL} \mathrm{~min}^{-1}$ (Obee and Brown, 1995; Zhang et al., 2003).

The $\mathrm{CO}_{2}$ yield rate was calculated by the following equation:

$\mathrm{CO}_{2}$ yield rate $=\frac{\left.C_{\mathrm{CO}_{2}} \text { (on }\right)-C_{\mathrm{CO}_{2}} \text { (off) }}{V / Q}$,

where the $C_{\mathrm{CO}_{2}}$ (on) and $C_{\mathrm{CO}_{2}}$ (off) (ppm) are the $\mathrm{CO}_{2}$ concentrations observed at the outlet of photoreactor by Q-Trak when the UV lamp is on and off, respectively; $V\left(\mathrm{~m}^{3}\right)$ the volume of photoreactor. $V / Q$ (s) the hydraulic retention time of the photoreactor, which represents the average time for a gas molecule to pass through the photoreactor. Since the diffusivity $(D)$ of $\mathrm{CO}_{2}(D=$ $\left.0.165 \mathrm{~cm}^{2} \mathrm{~s}^{-1}\right)$ is larger than that of $n$-hexane $\left(D=0.776 \mathrm{~cm}^{2} \mathrm{~s}^{-1}\right)$, iso-butanol $\left(D=0.0904 \mathrm{~cm}^{2} \mathrm{~s}^{-1}\right)$, mesitylene $\left(D=0.0729 \mathrm{~cm}^{2} \mathrm{~s}^{-1}\right), \quad m$-xylene $(D=$ $\left.0.0785 \mathrm{~cm}^{2} \mathrm{~s}^{-1}\right), p$-xylene $\left(D=0.785 \mathrm{~cm}^{2} \mathrm{~s}^{-1}\right)$, and toluene $\left(D=0.0842 \mathrm{~cm}^{2} \mathrm{~s}^{-1}\right)$ (Bird et al., 1960; Fuller et al., 1966), the rate determining step of $\mathrm{CO}_{2}$ yield is probably the surface reaction (at 


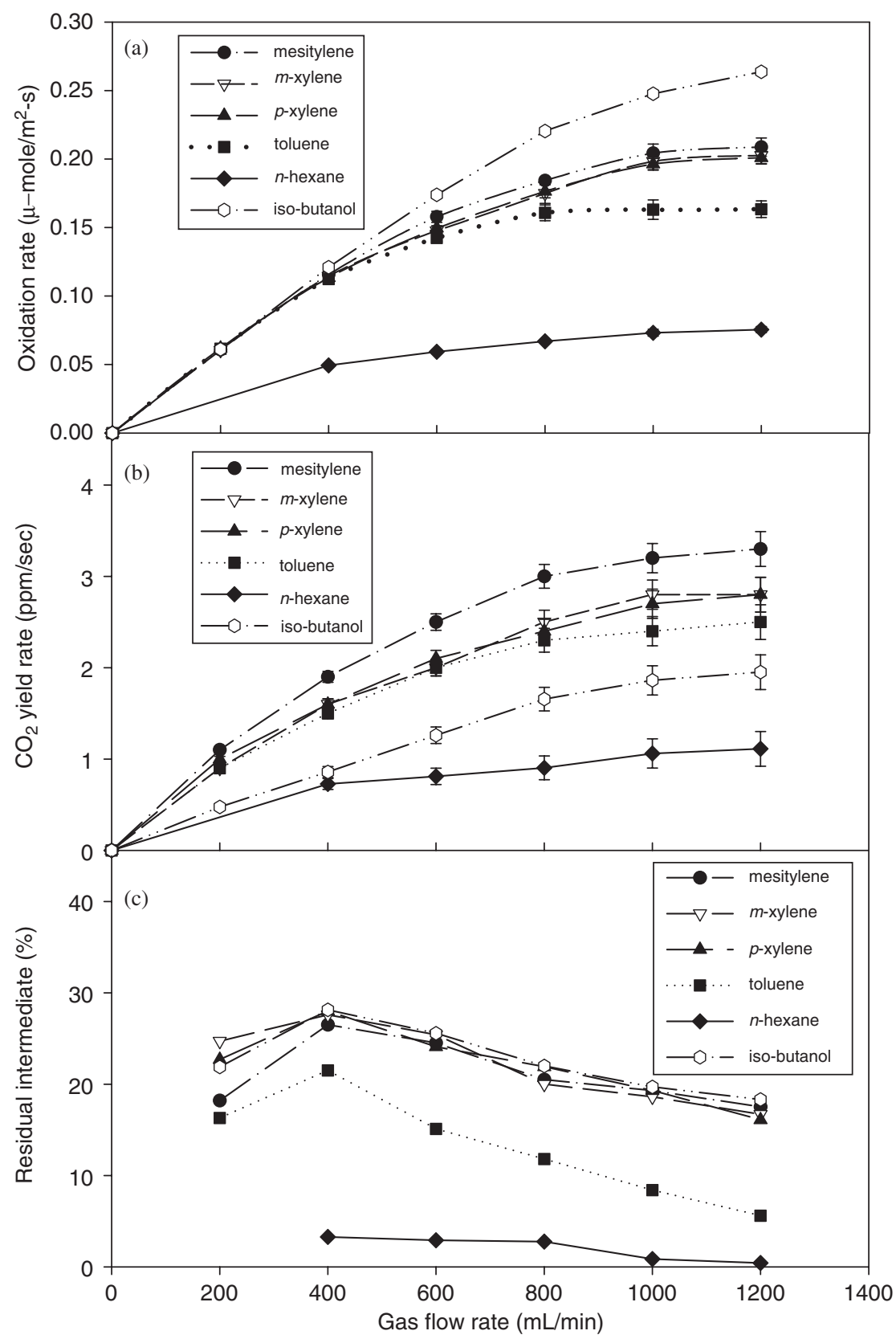

Fig. 2. (a) Effect of flow rate on PCO reaction rate, (b) effect of flow rate on $\mathrm{CO}_{2}$ yield rate, (c) effect of flow rate on residual intermediate (RH $50 \%, 25^{\circ} \mathrm{C}$, and $45 \mu \mathrm{W} \mathrm{cm}{ }^{-2} \mathrm{UV}-\mathrm{C}$ ).

reaction controlling condition) or the gas-phase mass transport of VOCs (at diffusion controlling condition). Therefore, the $\mathrm{CO}_{2}$ yield rate should correspond to the apparent oxidation rate of the primary VOC species or a secondary intermediate. Experimental results demonstrated that the $\mathrm{CO}_{2}$ yield rates of PCO reaction of $n$-hexane, iso- butanol, mesitylene, $m$-xylene, $p$-xylene, and toluene all increased with increasing flow rate and then asymptotically reached a plateau at flow rate $>1000 \mathrm{~mL} \mathrm{~min}^{-1}$, similar to that for the apparent oxidation rate, as shown in Fig. 2(b).

Some oxidized VOCs were not completely mineralized to $\mathrm{CO}_{2}$ and $\mathrm{H}_{2} \mathrm{O}$, and the partially oxidized 
VOCs remain as residual intermediates. The percentage of residual intermediate was calculated as follows:

residual intermediate $(\%)$

$$
\begin{aligned}
= & \frac{\left.\left(C_{\text {in }}-C_{\text {out }}\right)-\left[C_{\mathrm{CO}_{2}} \text { (on }\right)-C_{\mathrm{CO}_{2}}(\text { off })\right] / n}{C_{\text {in }}} \\
& \times 100 \%,
\end{aligned}
$$

where $n$ is the number of carbon atoms that VOCs molecule contains. As shown in Fig. 2(c), except for the gas flow rate above $200 \mathrm{~mL} \mathrm{~min}^{-1}$, the amount of the residual intermediates decreased as the gas flow rate increased. This result indicated that the amount of the residual intermediates might be influenced by the gas-phase mass transport rates and VOCs conversion. As the flow rate decreased, the retention time became larger and the gas-phase mass transfer rate became lower. The intermediates of PCO might accumulate at the active site and in the gas phase under these conditions. Thus, the amount of the residual intermediates increased. The exception under the flow rate of $200 \mathrm{~mL} \mathrm{~min}^{-1}$ might result from the high conversion of VOCs under very long retention time $(>31 \mathrm{~s})$. In this condition, the concentration of the VOCs near the outlet of the photoreactor became much lower than the inlet concentration. In this case, the long reaction time allowed for the oxidation and mineralization to $\mathrm{CO}_{2}$ and $\mathrm{H}_{2} \mathrm{O}$ of intermediates formed from the primary VOC species. In order to reduce the amount of residual intermediates, we suggest that the gas flow rate should be controlled above $1200 \mathrm{~mL} \mathrm{~min}^{-1}$.

\subsection{Kinetic equation}

Under the surface reaction controlled conditions, the experimental data agreed well with a $\mathrm{L}-\mathrm{H}$ model for bimolecular surface reaction with competitive adsorption as expressed below (Adamson, 1982):

$$
\begin{aligned}
r= & k \frac{K_{1} C_{\mathrm{VOC}}}{\left(1+K_{1} C_{\mathrm{VOC}}+K_{2} C_{w}\right)} \\
& \times \frac{K_{2} C_{w}}{\left(1+K_{1} C_{\mathrm{VOC}}+K_{2} C_{w}\right)},
\end{aligned}
$$

where $r\left(\mu \mathrm{mol} \mathrm{m}{ }^{-2} \mathrm{~s}^{-1}\right)$ is the oxidation rate, $k$ $\left(\mu \mathrm{mol} \mathrm{m}{ }^{-2} \mathrm{~s}^{-1}\right)$ the rate constant, $C_{\mathrm{VOC}}(\mathrm{ppm})$ the concentration of VOCs, $C_{w}(\mathrm{ppm})$ the humidity, and $K_{1}$ and $K_{2}\left(\mathrm{ppm}^{-1}\right)$ the Langmuir adsorption constants of VOCs and water vapor, respectively. The Langmuir adsorption constant represents the ratio of adsorbed concentration to gaseous concentration. A nonlinear, least-squares optimization procedure was used to fit the observed data. The best fit curves are shown in Fig. 3(a) and the regression results are presented in Table 1.

\subsection{Photocatalytic rate constant and VOCs- hydroxyl radical rate constant}

According to previous studies, oxidizing radicals, such as $\mathrm{OH}^{\circ}, \mathrm{HO}_{2}^{*}$ were detected in photocatalysis processes (Jaeger and Bard, 1979; Noda et al., 1992). It is generally accepted that the hydroxyl radical $\left(\mathrm{OH}^{*}\right)$ played the primary oxidizer attacking the organic compounds in PCO reaction (Adamson, 1982; Al-Ekabi et al., 1993; Augugliaro et al., 1999; Peral et al., 1997), thought the direct oxidation of VOCs by the holes may also occur. Therefore, the rate constants of $\mathrm{PCO}$ reaction may be proportional to the rate constants of the reaction of hydroxyl radical with VOCs $\left(k_{\mathrm{OH}}\right)$. As shown in Fig. 4 , the PCO rate constant $(k)$ of aromatic hydrocarbon has a positive linear relationship with $k_{\mathrm{OH}}$, and the linear regression equations are presented in Table 1. However, this positive linear relationship was not found between different classes of organic compounds (aromatic hydrocarbons, $n$-hexane and isobutanol).

\subsection{Langmuir adsorption constant and Henry's Law constant}

In the presence of humidity, the surface of titania is hydroxylated and hydroxyl groups are formed. Water molecule could be adsorbed on these hydroxyl groups via hydrogen bonding. By forming the $\mathrm{OH} \cdots \pi$ electron-type interaction, toluene also could be adsorbed on the same hydroxyl groups (Obee and Brown, 1995). Because of the similarity of chemical structures of the aromatic species used, the $\mathrm{OH} \cdots \pi$ electron-type interactions might be found in the adsorption of $m$-xylene, $p$-xylene, and mesitylene. Since water and all the VOCs were adsorbed on the same adsorption sites, a competitive interaction was anticipated. The degree of the competitive interaction between water and VOCs was dependent upon the relative chemical potential (Obee and Brown, 1995) or fugacity (f), and affects the Langmuir adsorption constant.

As noted above, the Langmuir adsorption constant of VOC $\left(K_{1}\right)$ is the ratio of adsorbed concentration $\left(C_{\mathrm{VOC}}\right.$ (ads), unit: $\left.\mathrm{g}-\mathrm{VOC} / \mathrm{g}-\mathrm{TiO}_{2}\right)$ to 


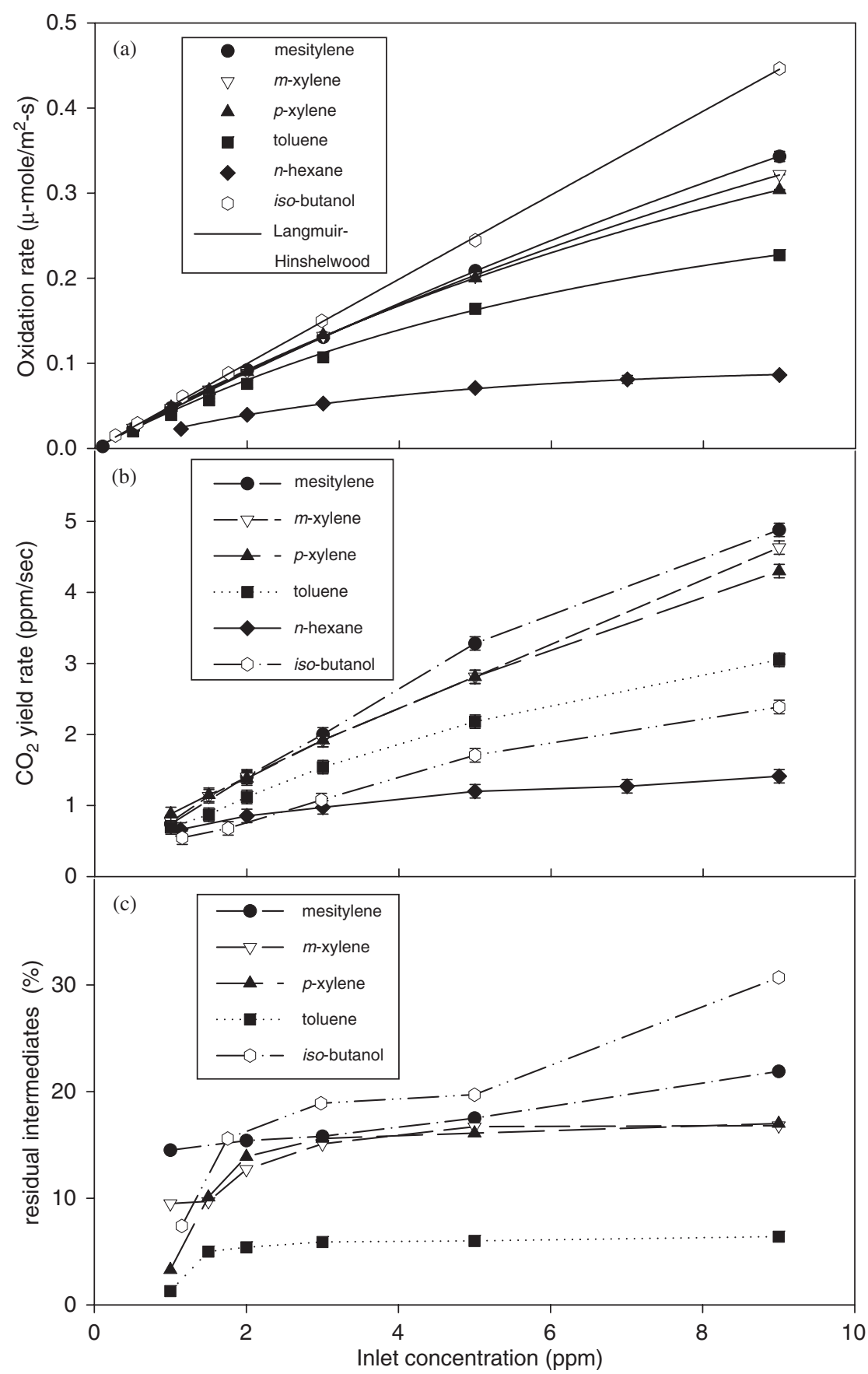

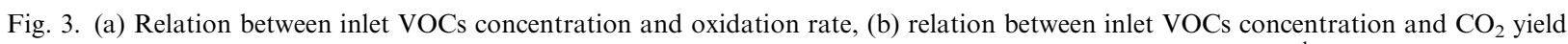
rate, (c) relation between inlet VOCs concentration and the residual intermediates (\%) (flow rate: $1200 \mathrm{mLmin}^{-1}, 25^{\circ} \mathrm{C}, \mathrm{RH} 50 \%$, and $45 \mu \mathrm{W} \mathrm{cm}{ }^{-2}$ UV-C).

gaseous concentration $\left(C_{\mathrm{VOC}}\right.$, unit: $\left.\mathrm{ppm}\right)$, that is $K_{1}=C_{\mathrm{VOC}(\mathrm{ads})} / C_{\mathrm{VOC}}$. Based on the fugacity approach, the concentration $(C)$ in a phase can be expressed as the product of fugacity $(f)$ and fugacity capacity ( $Z$ ), that is $C=Z f$. Under equilibrium conditions, the fugacities of the two phases (gasphase and the surface of the $\mathrm{TiO}_{2}$ ) must be equal. Thus, the Langmuir adsorption constant of VOC 
Table 1

VOC-OH ${ }^{\bullet}$ rate constants (at 298 K) (Seinfeld and Pandis, 1998; DeMore and Bayes, 1999), PCO rate constants, Henry's law constant (Lide

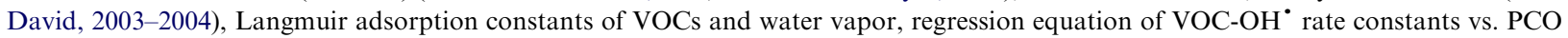
rate constants, and regression equation of Henry's law constant vs. Langmuir adsorption constants of aromatic hydrocarbons and water

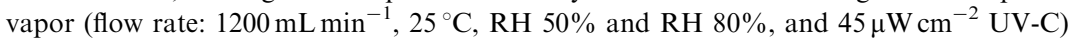

\begin{tabular}{|c|c|c|c|c|c|c|c|c|}
\hline \multirow[t]{2}{*}{ VOC } & \multirow[t]{2}{*}{$k_{\mathrm{OH}} \times 10^{12}\left(\mathrm{~cm}^{3}\right.$ molecule $\left.{ }^{-1} \mathrm{~s}^{-1}\right)$} & \multicolumn{2}{|c|}{$K\left(\mu \mathrm{mol} \mathrm{m}^{-2} \mathrm{~s}^{-1}\right)$} & \multirow[t]{2}{*}{$K_{\mathrm{H}}\left(\mathrm{kPa} \mathrm{m}^{3} \mathrm{~mol}^{-1}\right)$} & \multicolumn{2}{|c|}{$K_{1}\left(\mathrm{ppm}^{-1}\right)$} & \multicolumn{2}{|c|}{$K_{2} \times 10^{3}\left(\mathrm{ppm}^{-1}\right)$} \\
\hline & & RH $50 \%$ & RH $80 \%$ & & RH $50 \%$ & RH $80 \%$ & RH $50 \%$ & RH $80 \%$ \\
\hline Toluene & 5.96 & 1.20 & 1.03 & 0.66 & 1.35 & 1.20 & 2.41 & 1.44 \\
\hline p-xylene & 14.3 & 2.06 & 1.97 & 0.69 & 1.22 & 1.19 & 3.13 & 1.81 \\
\hline$m$-xylene & 23.6 & 2.67 & 2.51 & 0.73 & 1.11 & 1.04 & 3.89 & 2.29 \\
\hline Mesitylene & 57.5 & 3.99 & 4.00 & 0.78 & 1.02 & 0.95 & 5.61 & 3.44 \\
\hline$n$-hexane & 5.61 & 898 & & 4.14 & 0.069 & & $2.64 \times 10^{-5}$ & \\
\hline Iso-butanol & 8.47 & 97.8 & & 0.00273 & 0.207 & & 26 & \\
\hline
\end{tabular}

Regression equations for aromatic hydrocarbons

RH $50 \%$

$k=0.0507 \times k_{\mathrm{OH}}+1.1957$

$K_{1}=1 /\left(1.8896 \times K_{\mathrm{H}}-0.4935\right)$

$K_{2}=1 /\left(1635.5-1877.8 \times K_{\mathrm{H}}\right)$

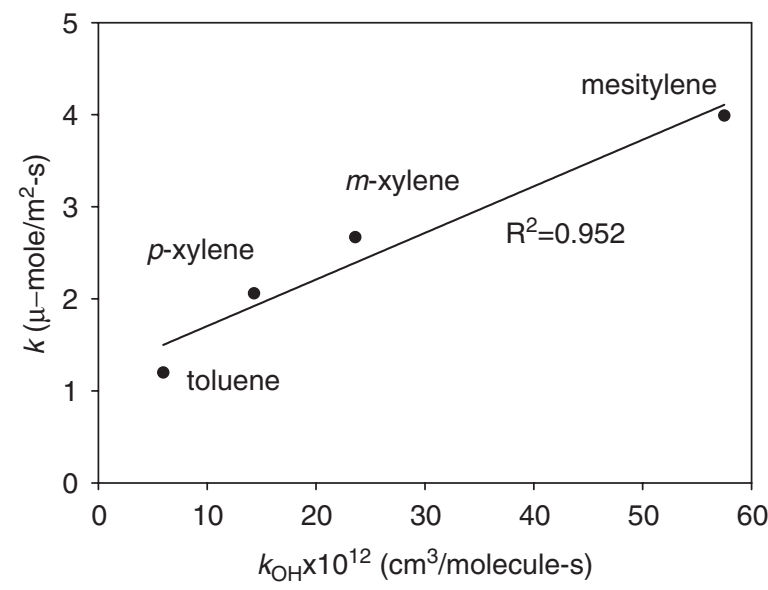

Fig. 4. Aromatic hydrocarbons- $\mathrm{OH}^{*}$ rate constant vs. $\mathrm{PCO}$ rate constant (flow rate: $1200 \mathrm{~mL} \mathrm{~min}^{-1}, 25^{\circ} \mathrm{C}$, RH $50 \%$, and $\left.45 \mu \mathrm{W} \mathrm{cm}^{-2} \mathrm{UV}-\mathrm{C}\right)$.

can be given as

$K_{1}=\frac{Z_{s}}{Z_{a} F}=\frac{K_{\mathrm{P}} \rho / K_{\mathrm{H}}}{F / R T}=\frac{\rho R T}{F} \times \frac{K_{\mathrm{P}}}{K_{\mathrm{H}}}$,

where $Z_{a}\left(\mathrm{~mol} \mathrm{~m}^{-3} \mathrm{kPa}\right)$ and $Z_{s}\left(\mathrm{kPa}^{-1}\right)$ are the fugacity capacities of gas phase and $\mathrm{TiO}_{2}$ surface, respectively, $F$ the conversion factor $\left(=24,500 \mathrm{ppm} \mathrm{m}^{3} \mathrm{~mol}^{-1}\right), \rho\left(\mathrm{kg} \mathrm{m}^{-3}\right)$ the density of $\mathrm{TiO}_{2}, R\left(=8.314 \times 10^{-3} \mathrm{kPa} \mathrm{m}^{3} \mathrm{~mol}^{-1} \mathrm{~K}\right)$ the gas constant, $T(\mathrm{~K})$ the temperature, and $K_{\mathrm{H}}$ $\left(\mathrm{kPa} \mathrm{m}^{3} \mathrm{~mol}^{-1}\right)$ the Henry's Law constant of VOC; $K_{\mathrm{P}}\left(\mathrm{m}^{6} \mathrm{~kg}^{-1} \mathrm{~mol}^{-1}\right)$ the partition coefficient of VOC between the surface of $\mathrm{TiO}_{2}$ and the surface bound water (MacKay, 1979; MacKay and Paterson, 1981; MacKay, 2001). Because the $\mathrm{TiO}_{2}$ surface is extremely hydrophilic, almost all the surface adsorption sites of $\mathrm{TiO}_{2}$ are occupied by water molecules in the presence of humidy. It is very difficult for hydrophobic organic compounds to be adsorbed on the surface of $\mathrm{TiO}_{2}$ in the presence of water. We presume that the effect of $K_{\mathrm{P}}$ is negligible and we focus on the relationship between Langmuir adsorption constant and Henry's Law constant. The results in Table 1 and Fig. 5 show that a positive linear relationship is between the reciprocal of Langmuir adsorption constant $\left(1 / K_{1}\right)$ and the Henry's Law constant. Oppositely, owing to the competition for the active site, the reciprocal of Langmuir competitive adsorption constant of water $\left(1 / K_{2}\right)$ reveals a strong negative relationship with the Henry's Law constant. However, the relationship demonstrated above is proved only within aromatic hydrocarbons. These relationships were not found between different classes of organic compounds.

\subsection{Photocatalytic pathways of VOCs degradation}

The degradation of alkane in photocatalysis is initiated by the abstraction of proton to form alkyl radical and $\mathrm{H}_{2} \mathrm{O}$ (Nair et al., 1992). This alkyl radical can react with $\mathrm{O}_{2}$ to give alkyl proxy radical:

$\mathrm{RH}+\mathrm{OH}^{\bullet} \rightarrow \mathrm{R}^{\bullet}+\mathrm{H}_{2} \mathrm{O} \stackrel{\mathrm{O}_{2}}{\longrightarrow} \mathrm{RO}_{2}^{\bullet}+\mathrm{H}_{2} \mathrm{O}$. 


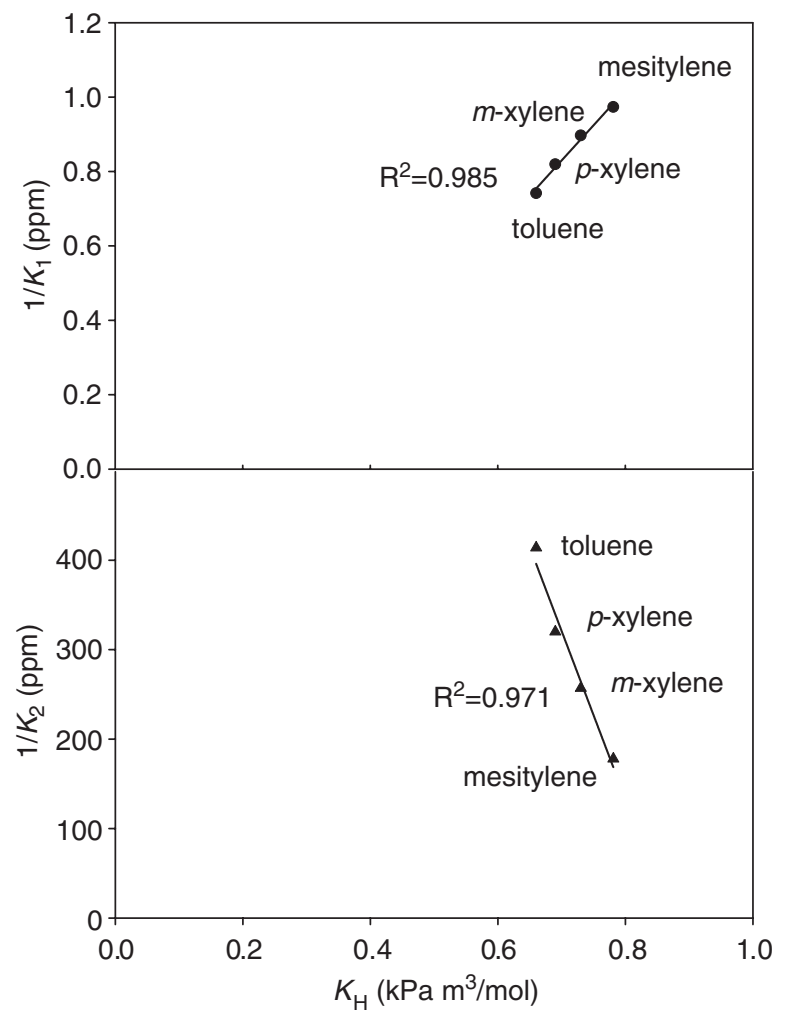

Fig. 5. Reciprocal of Langmuir adsorption constant of aromatic hydrocarbons $\left(1 / K_{1}\right)$ vs. Henry's Law constant and reciprocal of Langmuir adsorption constant of water $\left(1 / K_{2}\right)$ (flow rate: $1200 \mathrm{~mL} \mathrm{~min}^{-1}, 25^{\circ} \mathrm{C}$, RH $50 \%$, and $\left.45 \mu \mathrm{W} \mathrm{cm}{ }^{-2} \mathrm{UV}-\mathrm{C}\right)$.

Alkyl proxy radical reacts with alkane, or with $\mathrm{HO}_{2}^{*}$ radical to generate carboxylic acid:

$\mathrm{RO}_{2}^{\bullet}+\mathrm{RH} \rightarrow \mathrm{ROOH}+\mathrm{R}^{\bullet}$,

$\mathrm{RO}_{2} \cdot+\mathrm{H}_{2} \mathrm{O}^{\bullet} \rightarrow \mathrm{ROOH}+\mathrm{O}_{2}$.

The reduction of an alkyl chain primarily takes place via decarboxylation in accordance with the photo-Kolbe process (Izumi et al., 1981; Kraütler and Bard, 1978; Sakata et al., 1984):

$\mathrm{R}^{\prime} \mathrm{COO}^{-}+h^{+} \rightarrow \mathrm{R}^{\prime} \mathrm{COO}^{\bullet} \rightarrow \mathrm{R}^{\prime}+\mathrm{CO}_{2}$.

The initial step (abstraction of proton) of the degradation of alcohol in photocatalysis is easier than that of alkane, because the $\mathrm{C}-\mathrm{H}$ bond strength ( $\alpha$ carbon) of an alcohol is weaker than that of an alkane. The produced radical $\left(\mathrm{RCH}^{\circ} \mathrm{OH}\right)$ can react with oxygen to give hydroperoxyl radical $(\mathrm{RCH}(\mathrm{O}-$ $\left.\mathrm{H}) \mathrm{OO}^{\circ}\right)$. This radical can react with alcohol to give carboxylic acid (as the following):

$\mathrm{RCH}(\mathrm{OH}) \mathrm{OO}{ }^{\bullet}+\mathrm{RCHOH}^{-}$

$\rightarrow \mathrm{RCH}^{\bullet} \mathrm{OH}+\mathrm{RCOOH}$,

or form an aldehyde (as below):

$\mathrm{RCH}(\mathrm{OH}) \mathrm{OO}{ }^{\bullet} \rightarrow \mathrm{RCHO}+\mathrm{H}_{2} \mathrm{O}^{\bullet}$.

The self-reaction of two hydroperoxyl radicals generates a tetroxide, which rapidly breaks down to aldehyde and carboxylic acid:

$2 \mathrm{RCH}(\mathrm{OH}) \mathrm{OO}{ }^{\bullet} \rightarrow \mathrm{RCH}(\mathrm{OH}) \mathrm{O}_{4} \mathrm{CH}(\mathrm{OH}) \mathrm{R}$.

The formed aldehydes can be oxidized to their corresponding carboxylic acid. Carboxylic acid proceeds decarboxylation according to the photoKolbe reactions (Guillard et al, 2002).

The oxidation of aromatic hydrocarbons is initiated by the $\mathrm{OH}^{*}$ addition to the aromatic ring or $\mathrm{H}$-atom abstraction, and the addition reaction is a major pathway (of order 90\%). The addition reaction forms alkyl hydroxycyclohexadineyl radicals. These radicals can react with oxygen to give bicyclic radicals. Oxygen adds to the formed bicyclic radicals, producing bicyclic peroxy radicals. Bicyclic peroxy radicals may react with hydroxyl radical and lose one oxygen atom to form bicyclic oxy radical, which will undergo ring-fragmentation via $\beta$-scission reactions (Seinfeld and Pandis, 1998).

The H-atom abstraction pathway results primarily in the formation of aromatic aldehydes, which will be oxidized to the corresponding carboxylic acid. The carboxylic acid can be decomposed via photo-Kolbe decarboxylative route (Izumi et al., 1981).

The degradation of alkane by photocatalysis is more straightforward than that of alcohol or aromatic hydrocarbons. Therefore, the percentage of residual intermediates of $n$-hexane is less than that of iso-butanol or aromatic VOCs, as shown in Fig. 2(c). The ring-fragmentation products of toluene are smaller and simpler than that of mesitylene, $m$-xylene, and $p$-xylene. These smaller and simpler ring-fragmentation products are easier for decomposition. This explains why the percentage of residual intermediate is lower for toluene than for the other three aromatic VOCs investigated.

\subsection{Effect of VOCs concentration on $\mathrm{CO}_{2}$ yield}

The $\mathrm{CO}_{2}$ yield rates of PCO under different inlet VOCs concentrations are presented in Fig. 3(b). 
When the inlet VOCs concentration was smaller than $1 \mathrm{ppm}$, the $\mathrm{CO}_{2}$ yield was below the detection limit of Q-Trak (1 ppm), so the data cannot be reported here. As shown in Fig. 3(b), the $\mathrm{CO}_{2}$ yield rate increased while the inlet VOCs concentration and oxidation rate increased. The residual intermediates increased with the inlet VOCs concentration as presented in Fig. 3(c). The percentage of residual intermediates decreased with the number of carbons that aromatic hydrocarbons contain, as shown in Fig. 3(c). This may result from the different ring-fragmentation products of the four aromatic hydrocarbons investigated. The more carbon atom the aromatic hydrocarbon contains, the more complicated the ring-fragmentation products are. As a result, the percentage of residual intermediates increased with the carbon atom of aromatic hydrocarbons.

\section{Conclusions}

In this study, the gas-phase mass transfer strongly affected the oxidation rate for gas flow rate below $1000 \mathrm{~mL} \mathrm{~min}^{-1}$ (diffusion-controlling region). As a result of gas-phase mass transfer limitations, the unwanted residual intermediate concentrations decreased with increasing gas flow rate over the range between 400 and $1200 \mathrm{~mL} \mathrm{~min}^{-1}$. When gas flow rate was above $1000 \mathrm{~mL} \mathrm{~min}^{-1}$ (reaction-controlling region), the gas-phase mass transfer effect was negligible. Under this condition, the PCO kinetics were well described by a Langmuir-Hinshelwood model for competitive adsorption and bimolecular surface reaction. The rate constants of PCO for toluene, $p$-xylene, $m$-xylene, and mesitylene ranged from 1.22 to $4.00 \mu \mathrm{mol} \mathrm{m}^{-1} \mathrm{~s}^{-1}$ and were proportional to $k_{\mathrm{OH}}$. A strongly linear positive relationship was found between the reciprocal of Langmuir adsorption constant of VOCs and Henry's Law constant (in units $\mathrm{kPa} \mathrm{m}^{3} \mathrm{~mol}^{-1}$ ). Oppositely, the reciprocal of Langmuir adsorption constant of water revealed a strong negative relationship with Henry's Law constant. However, the relationships noted above were not found between different classes of VOCs ( $n$-hexane, iso-butanol, and aromatic VOCs investigated). According to the experimental results, the residual intermediates decrease as the inlet VOCs concentration decreased, hence PCO method is suitable for use in indoor environments to remove the VOCs pollutants investigated in this study.

\section{Acknowledgment}

The authors would like to thank National Science Council of Republic of China for funding this research project.

\section{References}

Adamson, A.W., 1982. Physical Chemistry of Surfaces, fourth ed. Wiley, New York.

Alberici, R.M., Jardim, W.F., 1997. Photocatalytic destruction of VOCs in the gas-phase using titanium dioxide. Applied Catalysis B: Environmental 14, 58-68.

Al-Ekabi, H., Butters, B., Delany, D., Holden, W., Powell, T., Story, J., 1993. The photocatalytic destruction of gaseous trichloroethylene and tetrachloroethylene over immobilized titanium-dioxide. In: Ollis, D.F., Al-Ekabi, H. (Eds.), Photocatalytic Purification and Treatment of Water and Air. Elsevier Science Publishers B.V., Amsterdam, pp. 719-725.

Augugliaro, V., Coluccia, S., Loddo, V., Marchese, L., Martra, G., Palmisano, L., Schiavello, M., 1999. Photocatalytic oxidation of gaseous toluene on anatase $\mathrm{TiO}_{2}$ catalyst: mechanistic aspects and FT-IR investigation. Applied Catalysis B: Environmental 20, 15-27.

Bird, R.B., Stewart, W.N., Lightfoot, E.N., 1960. Transport Phenomena. Wiley, New York.

Boeniger, F. Mark, 1995. Use of ozone generating devices to improve indoor air quality. American Industrial Hygiene Association Journal 56, 590-598.

DeMore, W.B., Bayes, K.D., 1999. Rate constants for the reactions of hydroxyl radical with several alkanes, cycloalkanes, and dimethyl ether. Journal of Physical Chemistry A 103, 2649-2654.

Fuller, E.N., Schettler, P.D., Giddings, J.C., 1966. A new method for prediction of binary gas-phase diffusion coefficient. Industrial \& Engineering Chemistry 58, 19-27.

Guillard, C., Théron, P., Pichat, P., Pétrier, C., 2002. Evaluation of 1-octanol degradation by photocatalysis and ultrasound using SPME. Water Research 36, 4263-4272.

Hines, A.L., Tushar, K.G., Sudarshan, K.L., Richand Jr., C.W., 1993. Indoor Air Quality and Control. Englewood Cliffs, New Jersey.

Izumi, I., Fan, F.R., Bard, A.J., 1981. Heterogeneous photocatalytic decomposition of benzoic acid and adipic acid on platinized $\mathrm{TiO}_{2}$ powder. The photo-Kolbe decarboxylative route to the breakdown of the benzene ring and to the production of butane. Journal of Physical Chemistry 85, 218-223.

Jaeger, C.D., Bard, A.J., 1979. Spin trapping and electron spin resonance detection of radical intermediates in the photodecomposition of water at $\mathrm{TiO}_{2}$ particulate systems. Journal of Physical Chemistry 83, 3146-3152.

Jones, A.P., 1999. Indoor air quality and health. Atmospheric Environment 33, 4535-4564.

Kim, Y.M., Harrad, S., Harrison, R.M., 2001. Concentrations and sources of VOCs in urban domestic and public microenvironments. Environmental Science \& Technology $35,997-1004$. 
Kraütler, B., Bard, A.J., 1978. Heterogeneous photocatalytic decomposition of saturated carboxylic acids on $\mathrm{TiO}_{2}$ powder. Decarboxylative route to alkanes. Journal of American Chemical Society 100, 5985-5992.

Lide David, R. (Ed.), 2003-2004. CRC Handbook of Chemistry and Physics, 81st ed. CRC Press, Cleveland, Ohio.

Mackay, D., 1979. Finding fugacity feasible. Environmental Science \& Technology 13, 1218-1223.

Mackay, D., 2001. Multimedia Environmental Models: The Fugacity Approach, second ed. Lewis Publishers Inc, Boca Raton.

Mackay, D., Paterson, S., 1981. Calculating fugacity. Environmental Science \& Technology 15, 1006-1014.

Maira, A.J., Yeung, K.L., Soria, J., Coeonado, J.M., Belver, C., Lee, C.Y., Augugliaro, V., 2001. Gas-phase photo-oxidation of toluene using nanometer-size $\mathrm{TiO}_{2}$ catalysts. Applied Catalysis B: Environmental 29, 327-336.

Mølhave, L., 1979. Indoor air pollution due to building materials. In: Proceedings of the First International Indoor Climate Symposium. Copenhagen, Denmark, p. 89.

Mølhave, L., Bach, B., Pedersen, O.F., 1986. Human reactions to low concentrations of volatile organic compounds. Environmental International 12 (1-4), 167-175.

Nair, M.R., Jacoby, W. A., Black, D. M., Milne, T.A., 1992. Detection of Intermediates from the gas-phase photocatalytic oxidation of trichloroethylene. In: Proceedings of the First International Conference of $\mathrm{TiO}_{2}$ Photocatalytic Purification and Treatment of Water and Air, London, Ontario, Canada, pp. $8-13$.

Noda, H., Oikawa, K., Kamada, H., 1992. ESR study of active oxygen radicals from photoexcited semiconductors using the spin-trapping technique. Chemical Society of Japan 65, 2505-2509.

Obee, T., Brown, R.T., 1995. $\mathrm{TiO}_{2}$ photocatalysis for indoor air applications: effects of humidity and trace contaminant levels on the oxidation rates of formaldehyde, toluene, and 1,3butadiene. Environmental Science \& Technology 29, 1223-1231.

Peral, J., Domènech, X., Ollis, D.F., 1997. Heterogeneous photocatalysis for purification, decontamination and deodorization of air. Journal of Chemical Technology and Biotechnology $70,117-140$.
Repace, J.L., 1982. Indoor air pollution. Environmental International 8, 21-36.

Sakata, T., Kawai, T., Hashimoto, K., 1984. Heterogeneous photocatalytic reactions of organic acids and water. New reaction paths besides the photo-kolbe reaction. Journal of Physical Chemistry 88, 2344-2350.

Salinaro, A., Serpone, N., Emeline, A., Ryabchuk, V., Hidaka, H., 1999. Relative photonic efficiencies and quantum yields in heterogeneous photocatalysis. Part II: Experimental determination of quantum yields. Pure and Applied Chemistry 71 (2), 321-335.

Sattler, L.M., Liljestrand, H.M., 2003. Method for predicting photocatalytic oxidation rates of organic compounds. Journal of the Air \& Waste Management Association 53, 3-12.

Seinfeld, H.J., Pandis, S.N., 1998. Atmospheric Chemistry and Physics. Wiley, New York.

VanOsdell, D.W., 1994. Evaluation of test methods for determining the effectiveness and capacity of gas-phase air filtration equipment for indoor air applications - phase I: literature review and test recommendations. ASHRAE Transactions 100 (2), 511-523.

WHO, 1989. Indoor Air Quality: Organic pollutants. Copenhagen, WHO Regional Office for Europe (EURO Reports and Studies No.111).

Wolkoff, P., Nielsen, G.D., 2001. Organic compounds in indoor air - their relevance for perceived indoor air quality? Atmospheric Environment 35, 4407-4417.

Wolkoff, P., Clausen, P.A., Wilkins, C.K., Nielsen, G.D., 2000. Formation of strong airway irritants in terpene/ozone mixtures. Indoor Air 10, 82-91.

Yang, R., Zhang, Y., Zhao, R., 2004. An improved model for analyzing the performance of photocatalytic oxidation reactors in removing volatile organic compounds and its application. Journal of Air \& Waste Management Association 54, 1516-1524.

Zhao, J., Yang, X., 2003. Photocatalytic oxidation for indoor air purification: a literature review. Building and Environment 30, 645-654.

Zhang, Y., Yang, R., Zhao,, R., 2003. A model for analyzing the performance of photocatalytic air cleaner in removing volatile organic compounds. Atmospheric Environment 37, 3395-3399. 